\title{
MIRADAS CRUZADAS HACIA LA POBREZA DESDE UNA PERSPECTIVA CRÍTICA TRANSDISCIPLINARIA
}

\author{
(Cross view from a transdisciplinary critical \\ perspective to poverty)
}

\author{
Denize Elena Garcia da Silva ${ }^{1}$ \\ (Universidade de Brasília - UnB) \\ Neyla Graciela Pardo Abril ${ }^{2}$ \\ (Universidad Nacional de Colombia - UNC)
}

\section{ABSTRACT}

The aim of this paper is to articulate, from a transdisciplinary perspective, theoretical conceptions that allow us to discuss the social question of poverty based on critical studies of discourse (ECD) that comprise cognitive dimension of context associated with properties of discursive genre, as well as register, style and rhetoric (van Dijk, 2007, 2008; Fairclough, 2003). These discourse properties as social practice contribute to the analysis of communicative events that emerge from 'situational contexts' and reflect 'cultural contexts'.

1. Doctora en Lingüística Hispánica por la Universidad Nacional Autónoma de México (UNAM). Profesora Asociada e investigadora junto al Programa de PósGrado en Lingüística de la Universidad de Brasília (PPGL/UnB). Coordinadora del Grupo Brasileiro de Estudos de Discurso, Pobreza e Identidades (CNPq), el cual hace parte de la Red Latinoamericana de Estudios del Discurso (REDLAD), formada por investigadores de Argentina, Brasil, Chile, Colombia, Venezuela y España.

2. Doctora en Filología-Lingüística Española. Profesora titular e investigadora del Instituto de Estudios en Comunicación y Cultura y del Departamento de Lingüística. Investigadora principal del Grupo Colombiano de Análisis del Discurso Mediático y coordinadora en Colombia de REDLAD. 
Key-words: poverty, context, discourse, genre, register, style, rhetoric

\section{RESUMO}

O objetivo do artigo é articular, desde uma perspectiva transdiciplinária, concepções teóricas que permitem discutir a questão social da pobreza com base em estudos críticos do discurso (ECD), sobretudo, os que relacionam a noção cognitiva de contexto com propriedades de gêneros discursivos, registros, estilos e retórica (van Dijk, 2007, 2008; Fairclough, 2003). Essas propriedades, vinculadas ao discurso como prática sócia,l contribuem para a análise de eventos comunicativos que emergem de 'contextos de situação' e refletem 'contextos de cultura'.

Palabras-chave: Gênero, discurso, pobreza, contexto, registro, estilo, retórica.

\section{Introducción}

El propósito de este artículo es presentar y discutir desde una perspectiva transdisciplinaria, centrada en los Estudios Críticos del Discurso (ECD), aspectos teóricos que permitan ubicar el fenómeno de la pobreza articulado a la noción de género discursivo. ${ }^{3} \mathrm{Si}$ se parte del supuesto de que los discursos son acciones capaces de representar cuestiones fundamentales para las sociedades, entonces el proceso de representación y configuración de los asuntos colectivos incluye las representaciones sobre las situaciones y los actores implicados en el evento comunicativo, es decir, los contextos. Se considera que el género discursivo es un elemento relacionado con los "contextos de cultura", donde se cruzan representaciones e ideologías que expresan proyectos de poder. Dado que la pobreza es una cuestión social compleja, desde

3. Las autoras agradecen a Juan Ruiz, estudiante del Departamento de Ciencia Política de la Universidad Nacional de Colombia y a Dra. Viviane Ramalho, profesora del Departamento de Lingüística, Portugués e Lenguas Clásicas de la Universidad de Brasília (UnB), por la colaboración de ambos en el desarrollo del presente trabajo. Ruiz es asistente de investigación y miembro del Grupo Colombiano de Análisis del Discurso Mediático. Ramalho es investigadora formada y miembro del "Grupo Brasileiro de Estudos de Discurso, Pobreza e Identidades" $(\mathrm{CNPq})$. Por supuesto, cualquier error en el ámbito de este estudio es de responsabilidad de las autoras. 
la perspectiva de su representación discursiva se podría relacionar con la noción de "contexto de situación" (Halliday \& Hasan, 1989).

En el marco de estas nociones quedan representados algunos factores que determinan o que dan significado a lo que en el acto de comunicación se posiciona. En este sentido, el discurso de la pobreza puede incluir el conjunto de representaciones sobre la carencia de recursos simbólicos y materiales indispensables para la autorrealización social, así como las representaciones que dan cuenta del carácter identitario de los sujetos implicados.

\section{2. 'Selvas de exclusión social' en un mapa de la moder- nidad tardía ${ }^{4}$}

Interesa hablar de "selvas" en un sentido metafórico, desde una realidad que pertenece a una problemática estructural en América Latina como lo es la pobreza, particularmente, en Brasil y en Colombia. Estos países tienen en común - además de ser parte de un mismo espacio geográfico y compartir la amazonía - la presencia de "selvas de exclusión”. Estas se entienden, en este trabajo, como escenarios de tensión permanente en los que se compite por los recursos simbólicos y materiales indispensables para vivir. Este concepto designa a las poblaciones que, por distintos factores socio-históricos, han sido marginalizados y excluidos del acceso a los recursos a los que tienen derecho en virtud su condición humana.

A este respecto Pardo Gil (2008:19) señala:

Las personas en situación de pobreza extrema constituyen hoy la mayoría en el mundo. El 54 por ciento del planeta vive en situación de pobreza. Un triste record histórico para la humanidad que seguramente no aparecerá en el Guiness. Ahora bien, esa mayoría no está en Europa ni en Estados Unidos, sino en el llamado patio de atrás: África, América Latina y algunos lugares de Asia como la India.

4. Para ampliar en el concepto de "selvas de exclusión” véase Pochmann y Amorin (2004). 
Aunque los datos referidos sean recientes, las discusiones acerca del tema de la pobreza han generado controversia desde hace varios siglos. El concepto de pobreza, desde su génesis ideológica, se encuentra "articulado a distintos factores que van desde de lo mítico a lo religioso y desde allí al orden socio-político y económico" (Pardo N, 2008:21).

Si se hace una aproximación a los conceptos que forman parte del campo semántico de la pobreza, articulados a factores simbólicos y materiales, se encuentran pares conceptuales que conllevan una pretensión de universalidad. Esto se evidencia en dicotomías tales como "pobreza y riqueza", "igualdad y desigualdad" e "inclusión y exclusión", entre otras. Lo que ha sugerido Silva (2007: 51), en el estudio "Identidades enfraquecidas versus cidadania cultural", puede ser retomado para dar cuenta de las maneras en que se estabilizan significados sociales y sus efectos en la vida social: "mais do que pistas linguístico-discursivas que remetem a uma ideia de oposição, essas formas de expressão significan representações que fazem parte de nossa memoria social".

Las unidades léxicas asociadas con el concepto de pobreza son portadoras de significados que se han consolidado a lo largo de la historia. Estos significados vinculan la pobreza, la desigualdad y la exclusión con expresiones que indican 'ausencia de libertad'. La carencia de libertades incluye, entre otros factores, la imposibilidad de acceder a ingresos suficientes, educación, salud, condiciones medioambientales sanas, empleo, cultura, participación política y, en general, capital social.

En sus estudios sobre vulnerabilidad y exclusión social Bruto da Costa (2006: 23), señala:

Como se sabe, a liberdade é hoje universalmente reconhecida como um direito humano fundamental. Nestas condições, o relacionamento da pobreza com a liberdade leva-nos a concluir que, pelo menos enquanto negação da liberdade, a pobreza configura uma situação de negação de direitos humanos fundamentais... A relação da pobreza, em geral, e da fome, em particular, com a liberdade também serve para mostrar que a privação, mesmo quando seja apenas na forma elementar de privação 
alimentar, não é apenas material. Repercute-se noutras formas de necesidades humanas, materiais e imateriais.

En el contexto brasileño, son varios los estudios en ciencias sociales que han abordado la exclusión como fenómeno social. Porchmann y Amorin (2004) elaboran un estudio sociológico, en el que se incluyen datos de indicadores sociales y económicos, a partir de los cuales dibujan un mapa de la desigualdad y la exclusión en Brasil. Rocha (2005), antes de tratar de indicadores económicos, discute los conceptos de pobreza absoluta y pobreza relativa. Vincula la pobreza absoluta a la cuestión de sobrevivencia física y sugiere que la pobreza relativa se relaciona con las necesidades que giran en torno al modo de vida predominante en una sociedad. En estas dos nociones, da cuenta de las formas en que la pobreza y la desigualdad constituyen dos aspectos de un mismo problema.

Para el caso colombiano, se destaca el trabajo de Corredor (2004), que aunque reflexiona el problema de la pobreza desde la economía, articula tres perspectivas para su comprensión y análisis. La pobreza como un fenómeno vinculado a la dimensión material, como un acto de exclusión social sistemático, y como una condición eliminadora de potencialidades y derechos. Este breve panorama que puede extenderse a toda América Latina señala que el estudio sobre la pobreza no puede limitarse a la descripción de variables sociales expresadas en cifras, sino que debe articular tres dimensiones de las formas del proceder social: la exclusión, la inequidad y la discriminación.

\section{La noción de contexto}

Como se ha indicado, las reflexiones sobre el discurso de la pobreza incluye el conjunto de representaciones de las que dispone una comunidad para otorgar significado e interpretar lo que se expresa en relación con este problema social. La noción de contexto cobra relevancia, pues desde la perspectiva de van Dijk (2007, 2008), hace énfasis en los aspectos pertinentes de la situación local y global 
de interacción tenidos en cuenta por los participantes en la situación de comunicación. La conceptualización de esta categoría ubica los elementos que la constituyen en el nivel cognitivo y, por lo tanto, en el nivel de las representaciones que los seres humanos elaboran en el proceso de la comunicación. Se supera la contextualización del plano de las descripciones fácticas de los elementos constitutivos de la interacción, para dimensionarlos en el plano cognitivo.

Los contextos son constructos mentales a través de los cuales los interlocutores y los analistas reconocen experiencias, percepciones, opiniones, conocimientos, puntos de vista y emociones en relación con la situación comunicativa. El contexto se origina en los modelos de experiencia ${ }^{5}$ y, en este sentido, es subjetivo. Simultáneamente, los contextos son representaciones sociales de las que disponen los participantes de la acción comunicativa, en relación con conocimientos comunes, actitudes e idearios propios de los grupos. Desde este punto de vista, son intersubjetivos y tienen la función de garantizar los grados de adecuación requeridos para que los entornos cognitivos y socioculturales se articulen en la interacción comunicativa, en consecuencia, tienen una función pragmática y semántica (Van Dijk, 2008).

Para este trabajo, la teoría cognitiva del contexto permite reconocer las relaciones entre los diferentes sistemas cognitivos que se hacen evidentes cuando se expresa una comunidad en relación con los problemas que son definidos como relevantes. También permite identificar las condiciones en las que los discursos son apropiados, de acuerdo con situaciones sociales e intereses concretos. En este sentido, se puede afirmar que los discursos ponen en relación las representaciones de experiencias personales o subjetivas, y las representaciones que los participantes de un acto de comunicación, elaboran de las situaciones comunicativas concretas o intersubjetivas. Para los ECD las condiciones sociales involucradas y representadas en la comunicación, así como

5. Por modelo de experiencia se entiende el conjunto de representaciones que un sujeto elabora en relación con su manera particular de relacionarse con el mundo. Para más información sobre este concepto véase van Dijk (1998). 
el conjunto de reglas semántico-pragmáticas, permiten identificar las relaciones de poder. Por lo tanto, las representaciones de la autoridad, el rol, la cortesía y el estatus, entre otras, operan sobre una base cognitiva y social. En consecuencia, son relaciones relevantes para interpretar los fenómenos sociales que se expresan y producen en el contexto.

Un principio fundamental de los ECD señala que las relaciones entre el discurso y la sociedad pueden ser reconocidas, por una parte, en el contexto, a través de la variación en todos los niveles de los eventos comunicativos y, por otra parte, a través de ciertas propiedades del discurso como el género, el registro y el estilo. Estas propiedades del discurso como práctica social contribuyen a dar cuenta de la forma en que se representan las situaciones comunicativas.

Analizar el género en el discurso sobre la pobreza se explica en la necesidad de comprender los modos recurrentes no sólo de "actuar y relacionarse con el otro", sino además "actuar sobre el otro", lo cual presupone la necesidad de discutir relaciones de género, poder e ideología. Como sugieren Chouliaraki \& Fairclough (1999:96), "the question of how to dialogue and act with others who are different is quite as urgent in late modern societies as the question of who I am or who we are". El conocimiento de las propiedades del discurso, así como las representaciones meta-cognitivas, pueden constituirse en formas de mediación que, en determinadas condiciones, favorecen diálogos que tematizan la pobreza y la discriminación (Silva, 2009). Es justamente el diálogo en favor de los excluidos lo que va a sustentar nuestras miradas cruzadas.

Como ha sugerido Marcuschi (2005), el papel de la actividad discursiva en el ejercicio del control social ocurre por medio del género. Desde muy temprano los seres humanos apropian culturalmente el uso de los diversos géneros y en el proceso de socialización aprenden a seleccionar los más adecuados a la situación de interacción en la que participan. Esto incluye, tanto el rol del lenguaje en una actividad

6. "La cuestión de cómo dialogar e interactuar con otros que son diferentes, es casi tan urgente en las sociedades de la modernidad tardía como la pregunta respecto a quién soy yo o quién somos nosotros" (trad. de las autoras). 
social específica, como el tipo de actividad desarrollada, los temas correlacionados y las relaciones sociales (Silva \& Ramalho, 2008:21).

\section{El género discursivo}

El género discursivo se entiende como el conjunto de propiedades y recursos que permiten dar identidad o tipificar una expresión discursiva ubicada históricamente. Es una interacción o actividad comunicativa que entreteje propiedades, que pueden ser rastreadas en el registro, el estilo y la retórica, entre otras posibilidades lingüístico-discusivas. En la vida contemporánea estas expresiones discursivas se hacen cada vez más difusas y, por lo tanto, los discursos pueden tipificar géneros híbridos o difusos.

De acuerdo con Marcuschi (2008: 19), género es al mismo tiempo:

- una categoría cultural

- un esquema cognitivo

- una forma de acción y organización cultural

- una estructura textual

- una acción retórica

Cada unos de esos indicadores puede ser considerado como un aspecto de observación. Pero más allá de la complejidad que se pueda formular en la conceptualización de género discursivo, se mantiene vigente la manera como Bajtin (1985) desglosa esta categoría y la pone en relación con los factores que determinan el sentido del discurso, incluido en concepto de contexto, en la perspectiva aquí adoptada. Los géneros discursivos

[ ] reflejan las condiciones especificas y el objeto de cada una de las esferas no solo por su contenido (temático) y por su estilo verbal o sea, por la selección de los recursos léxicos, fraseológicos y gramaticales de la lengua, sino, ante todo, por su composición y estructuración. Los tres momentos mencionados, contenido temático, estilo y composición, están vinculados indisolublemente en la totalidad [ ] y se determinan, de un modo semejante, por la especificidad de una esfera de comunicación [ ] (Bajtin, M. 1985: 248). 
Dado que interesa en este trabajo estudiar el género, de acuerdo con van Dijk (2008) y Marcuschi (2005, 2008), esta propiedad del discurso se entiende como un tipo de expresión, interacción, actividad verbal o evento comunicativo. El análisis de los géneros como acción social se centra en la explicación de las propiedades del discurso, observadas en la materialidad discursiva. Por lo tanto, se identifican fenómenos lingüísticos que se anclan en el uso gramatical o el registro, el estilo y la retórica. A través de estas propiedades discursivas es posible analizar y explicar los escenarios, los participantes (sus roles, identidades y relaciones), el tipo de actividad social involucrada (económica, política y religiosa, etc.) y su fundamento cognitivo (objetivos, conocimientos, creencias e ideologías). El análisis del género implica reconocer aspectos que se hallan representados en el contexto.

\subsection{Contexto, género y registro}

En este estudio, se considera el registro como una realización del género. Ambos conceptos se encuentran dentro de la dimensión cognitiva del "contexto". Desde esta perspectiva, el género es determinado por el contexto sociocultural, ubicado en un plan de "orden superior" (macro), mientras que el registro es determinado por el contexto situacional en una instancia local (micro) o de "orden inferior”, como sugieren Ghio y Fernández (2008:54).

El concepto de registro frecuentemente se asocia con los usos del lenguaje, en relación con los diversos modos y situaciones. En la perspectiva de la Lingüística Sistémico Funcional -LSF -, la categoría registro es caracterizada en términos de tres componentes o variables contextuales: campo, tenor y modo ${ }^{7}$. De acuerdo con Meurer (2006: 168), "na LSF, estas três variáveis são vistas como responsáveis ou determinadoras do registro usado em um texto, isto é, a configuração de elementos lexicogramaticais convencionalmente usados na realização de uma determinada significação".

7. Tanto en Brasil como en Portugal, la traducción de la palabra inglesa tenor es relaciones. Involucra los roles de los participantes, así como el proceso de interacción. 
El campo involucra el acontecimiento en curso, o la actividad en el proceso de realización. La denominación tenor concierne a los roles, así como a la interacción entre los participantes. El modo, por su parte, comprende el canal (fónico/gráfico), la modalidad (escrito/oral) y el medio (eletrónico u otro) del texto. Las tres variables se encuentran asociadas a las metafunciones del lenguaje que se identifican en los textos: la ideacional (como proceso); la interpersonal (acto de habla); y la textual (mensaje) conforme sugiere Halliday (1994).

En el siguiente cuadro se sintetizan las relaciones entre las variables de contexto, las macrofunciones y las realizaciones lexicogramaticales.

\begin{tabular}{|c|c|c|}
\hline $\begin{array}{c}\text { Registro } \\
\text { (Variables de contexto) }\end{array}$ & Macrofunciones & $\begin{array}{c}\text { Realizaciones } \\
\text { léxico-gramaticales }\end{array}$ \\
\hline Campo & Ideacional & Transitividad \\
\hline Tenor/Relaciones & Interpersonal & Modo y Modalidad \\
\hline Modo & Textual & Tema y Rema \\
\hline
\end{tabular}

Adaptado de Barbara y Macedo (2009: 91)

En este apartado se ilustran las aplicaciones de los tres componentes de registro con el propósito de analizar y discutir estas variables contextuales. Para el análisis, se toman reflexiones presentes en el trabajo "Grammar of Visual Design", de Kress y Leeuwen (1996), cuya propuesta parte de las macrofunciones del lenguaje de Halliday (1994).

Una parte del corpus seleccionado para el análisis se retoma del espacio público en la ciudad de São Paulo. Comprende un soporte de género mediático, es decir, un outdoor que fue parte de la campaña de una empresa de publicidad, para celebrar el aniversario de la capital ${ }^{8}$.

8. La pieza elaborada por la empresa publicitaria constituye una forma de protesta y una respuesta a la decisión del alcalde de la ciudad de São Paulo, cuya actuación respecto la contaminación visual culminó en la Ley $\mathrm{N}^{\circ} 14.223$. Esta Ley fue sancionada el 26 de diciembre de 2006, mediante la cual se exige retirar los outdoors del espacio capitalino. 
La imagen, que constituye una pieza acoplada, involucra elementos de la variable contextual modo. Además del outdoor, se construyen múltiples discursos que se fusionan para elaborar un nuevo mensaje, cuyo campo de acción forma parte de lo que se puede caracterizar como "poder corporativo". Este concepto hace parte de lo que van Dijk (2001:40) denomina "discursos dominantes de una compañía comercial", que para el caso del texto presentado corresponde al de una empresa publicitaria (Famiglia).

Se pude afirmar con Eggins y Martin (2000: 338) que "el contexto se introduce 'en' el texto debido a que influye sobre las palabras y estructuras que sus autores utilizan". De esta manera, el tema de la pobreza está implícito en el texto como un "conocimiento supuesto".

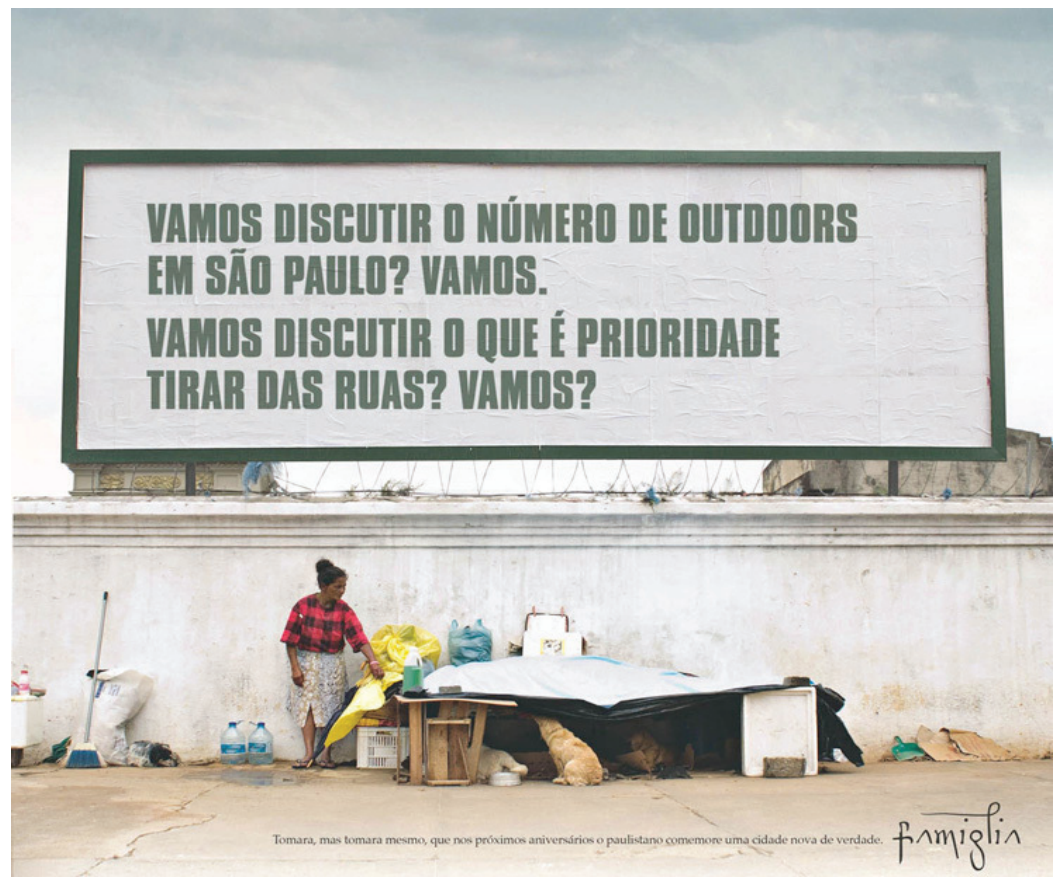

Fuente: http://bp2.blogger.com/GGlC2YPPyV4/RilX79b0zkI/.jpg 
En la parte superior de la imagen, el texto tiene una implicación ideológica compleja. Más que una protesta, exhibe una denuncia y una crítica implícita, mediante la invitación en forma de apelación, formulada en la modalidad interrogativa por pares de enunciados. La acción verbal, que aparece en la posición de tópico, se encuentra en primera persona del plural, lo cual contribuye a la interacción con el lector potencial (tenor).

Las dos partes de la composición evocan la siguiente estructura textual (modo): real/ideal, lo que sugiere una sensación de contraste u oposición entre texto (mensaje ideal) e imagen (mensaje real), de donde se infiere una inversión de valores. La sección superior (el texto en el outdoor) implica una apelación emocional, mientras la parte de abajo es más informativa, una vez que pone en evidencia la situación de los que viven en la calle. La presencia de la mujer en la escena tiene un doble rol: al mismo tiempo que figura como participante 'afectada', puede ser considerada como 'meta', en tanto sufre la acción ejecutada por el participante responsable por la composición texto/imagen. En síntesis, el texto/imagen en análisis sugiere una bidirecionalidad en términos de meta-función textual. En este proceso se entretejen valores ideológicos que refuerzan, por un lado, la intencionalidad de la entidad responsable del outdoor - la empresa Famiglia. Por otro lado, la foto como un todo indica una coherencia en términos de conexión semántica y pragmática entre texto e imagen. Por consiguiente, la composición pone de relieve la ruptura de la cohesión social, marcada por la pobreza en la calle.

Con base en la LSF, Kress \& van Leeuwen (1996) sugieren un modelo teórico-metodológico para los estudios críticos de textos multimodales, o sea, textos que comprenden diferentes sistemas semióticos del lenguaje. La "gramática del lenguaje visual" nos permite describir e identificar modos culturalmente definidos. Es decir, cómo imágenes que se articulan en composiciones visuales son concebidas en términos de las mismas macrofunciones del lenguaje verbal (ideacional, interpersonal y textual). Como ocurre en el lenguaje verbal, imágenes actúan como forma de representación, como intercambio de experiencia y como mensaje. Sin embargo, lo 
que en el lenguaje verbal es realizado, por ejemplo, por diferentes clases de palabras y estructuras semánticas, en el lenguaje visual se realiza por diferentes colores y estructuras composicionales. El design visual como representación, relacionado con la variable del campo (metafunción ideacional), puede ser analizado a partir de dos tipos de estructura: narrativa y conceptual. Estructuras visuales que representan acciones, eventos, procesos de cambio y arreglos espaciales transitorios son consideradas narrativas. Mientras estructuras conceptuales comprenden participantes que no ejecutan acciones dentro de imágenes, son representados en términos de clase e identidad, es decir, desde sus rasgos y características atribuidas colectivamente.

Ahora bien, el material empírico aquí analizado comprende una imagen en que la mujer, aunque señala un movimiento con la mano, pude ser considerada solamente como participante de un tipo de estructura visual conceptual, esto es, como representante de una clase: "habitante de la calle". Ella representa a un conjunto mayor de personas y familias que viven en situación de calle en la ciudad de São Paulo, Brasil.

Como explican Kress \& van Leeuwen (1996), en la comunicación visual el tipo de interacción depende de la naturaleza del contacto visual establecido entre los participantes representados - es decir, personas, lugares y cosas que constituyen temas de la comunicación - y los participantes interactivos que participan de la comunicación. El design visual enfocado como intercambio de experiencia, de acuerdo a la macrofunción interpersonal del lenguaje, puede ser analizado según el contacto visual entre otras categorías. Asociadas a textos verbales o imágenes pueden sugerir demandas en intercambios de actividades $u$ ofertas en intercambios de conocimiento/información. En imágenes en las que participantes representados miran directamente hacia el lector, vectores formados por la línea de los ojos conectan los primeros con el lector (viewer), participante interactivo. En esa configuración visual, el participante representado, de quien el vector (línea de la mirada de los ojos) emana, de dirige hacia al participante en 
interacción y demanda algo con ello. El intercambio establecido, en este caso, es de actividad.

En las configuraciones visuales en las que el objeto de la mirada no es el lector, sino el participante representado que es observado por el viewer, no existe contacto directo entre participantes representados e interactivos. El intercambio es de conocimiento. Los participantes representados figuran como ítems de información, como si fueran objetos de contemplación. En el caso de la composición objeto de éste análisis, la mujer y los perros son representados como ítems de información. Esto indicia la estructura conceptual señalada anteriormente: la situación de la vida en la calle solamente como objeto de información de la publicidad (Kress \& van Leeuwen, 1996).

El design visual como mensaje, asociado a la macrofunción textual, puede ser investigado de acuerdo con el valor de la información. La ubicación de elementos visuales en las diversas zonas de una composición visual, implica valores de información específicos. La ubicación de la información hacia la derecha o hacia la izquierda tiene valores distintos de significación en la lectura occidental. Así, los elementos posicionados a la izquierda son representados como "valores dados", es decir, como información ya conocida por el lector, que se articula al "tema" del lenguaje verbal. Los elementos ubicados a la derecha son representados como "valores nuevos", lo que no es conocido por el lector, razón por la cual debe recibir más atención.

En la composición objeto de estudio, lo "nuevo" es un texto ubicado en la parte inferior hacia la derecha, formado por un único complejo oracional, seguido del logo o marca de la empresa, como si fuera una firma en una tarjeta que se envía a las personas en fechas especiales.

“Tomara, mas tomara mesmo, que nos próximos aniversários o paulistano comemore uma cidade nova de verdade. Famiglia".

Se trata de un mensaje cuya fuerza, además de una carga actitudinal de crítica implícita, conlleva una valoración de afecto y deseo, señalada por la topicalización de la expresión: tomara (Ojalá), 
una interjección cuya función sirve para apelar al interlocutor. La expresión es enfatizada en seguida -mas tomara mesmo-. De acuerdo con Martin (2010: 141),

[...] tenemos que tener presente que los sentimientos siempre son acerca de algo, siempre son actitudes interpersonales hacia la experiencia ideacional. Y la investidura de actitud sobre la experiencia tiene que ser manejada por etapas - por medio de recursos textuales - porque gestionar una comunidad (ideológica) es un proceso dinámico, que se completa a medida que el texto avanza, en una mirada de discursos que materializan la comunión de la vida cotidiana e institucional.

En este sentido, los recursos textuales utilizados hacen avanzar el enunciado en términos de metafunción interpersonal en la medida en que el mensaje desafía el viewer a compartir los deseos de 'buena suerte'. Por medio de un discurso próximo al lenguaje cotidiano, el material publicitario se vale de la imagen para denunciar y defenderse. Además se utilizan elementos verbales para expresar una proposición que "gestiona" a la comunidad -los capitalinos-, articulada a una situación. Antes de sacar los outdoors de las calles (una acción que favorecería a los grupos dominantes), es necesario resolver la situación de las personas que, en situación de desposesión, habitan la calle. Esto puede contribuir a la garantía de uno de los derechos básicos previstos en la Ley Mayor - la habitación - e incentivar "la comunión de la vida cotidiana e institucional" a la vez.

\subsection{Género y estilos}

En este apartado, se asocia el estilo al género por medio de la noción de ethos discursivo. De acuerdo con Fairclough (2003: 26), se considera que los estilos implican la identificación de identidades personales o sociales. Se reconoce que los estilos pueden ser caracterizados también por una serie de rasgos lingüísticos. Un acercamiento a la forma del enunciado - Tomara, mas tomara mesmo, que nos próximos aniversários o paulistano comemore uma cidade 
nova de verdade - permite observar que se trata de un mensaje que señala el ethos discursivo de la empresa. El modo gramatical predominante es de declaración, aunque utilizada como fórmula de despedida. El vocabulario elegido sugiere la identificación social de la institución y su reacción contra una decisión que surge de instancias político-administrativas. Se observa la manera como son lexicalizados los sentimientos de deseo, sea en la expresión interjectiva 'tomara, mas tomara mesmo' (ojalá, pero ojalá mismo), o en la forma verbal en el modo subjuntivo (comemore), selecciones que reflejan el eje de la modalidad deóntica.

Al respecto, señala van Dijk (2003: 162), "el estilo puede definirse como el conjunto de propiedades formales del discurso que son una función de los modelos contextuales, como la lexicalización, el orden de las palabras y la entonación”. Al aproximar el diálogo entre los ECD con la LSF, Fairclough (2003) sugiere que un texto, además de involucrar simultáneamente las funciones ideacional, interpersonal (identitaria y relacional) y textual, debe ser considerado bajo el prisma de tres tipos de significados del discurso: como acción (por medio de géneros), representación (por medio de discursos) e identificación (por medio de estilos).

La identificación concierne a los principios éticos, es decir, a las relaciones de uno consigo mismo y con el otro. En este sentido, los estilos son maneras de identificación, que presuponen identidades sociales o personales particulares, además de la retórica que puede configurarse en la utilización de un género discursivo específico.

\subsection{Género y retórica}

La utilización de un género discursivo específico es una decisión analizable en dos sentidos. Por una parte, desde el punto de vista de las propiedades socio-comunicativas de los actos discursivos, para establecer una determinada forma de interlocución a partir de la apropiación de maneras concretas de comunicar (estilos). Por otra parte, desde el punto de vista cognitivo, para analizar la importancia que puede tener 
la utilización de un género en relación con el valor que se le otorga a los acontecimientos, las acciones y los actores que son representados a través del discurso. Desde el campo de los ECD, los géneros discursivos indican qué información es importante o interesante, qué información es susceptible de ser topicalizada, cuales son los recursos y las estrategias discursivas validas y cuáles son las claves nemotécnicas que deben ser utilizadas. Los diferentes géneros asumen funciones socio-comunicativas y cognitivas, en virtud de su especificidad y en función de las maneras en que contribuyen a movilizar representaciones sobre la realidad, que tienen efectos de poder.

Se integra al concepto de género una propiedad que permite rastrear lo que, en tradiciones lingüísticas distintas, se ha denominado tipo de texto o modo discursivo y que, como otras propiedades lingǘstico discursivas, pueden aparecer fusionadas, contribuyendo a potenciar el género. La narración, la argumentación y la conversación son recursos que dan cuenta de tipos de estructuras del discurso, que contribuyen a definir las propiedades del género.

Dentro de los recursos discursivos usualmente se usan estructuras o estrategias retóricas que contribuyen a definir las formas de organización de los discursos, así como las maneras en que son condensados los significados. Desde un plano representacional, las estructuras retóricas que se implican en la utilización de determinados géneros discursivos, están relacionadas con el uso estratégico del lenguaje para focalizar ciertos aspectos que son representados como relevantes, o para minimizar asuntos que se constituyen en puntos de tensión en una sociedad. Los nexos entre género y retórica proceden del carácter puntual que adquieren los actos discursivos en una situación de comunicación; los recursos apropiados, las estrategias desplegadas y las formas puntuales de organización de la información en un discurso.

Las estructuras retóricas han sido estudiadas con frecuencia, para dar cuenta de los múltiples e innumerables artificios discursivos que se usan para dar ornamento a lo que se expresa, agrupados en los tropos y las figuras. Esta posición clásica se halla en trabajos desarrollados por Leech (1969), Todorov (1974), el Grupo $\mu$, (1993), 
Albaladejo (1989) y en otra perspectiva, en los trabajos más recientes de van Dijk (1981), Dressler \& Beaugrande (1981) y Eco (1983), entre otros. La retórica constituye en los ECD un asunto esencial si se tiene en cuenta que en los distintos niveles de uso lingüístico y semiótico, no sólo forma parte de los procesos que se implican para convencer o desempeñar una función argumentativa, sino que sirve al proceso de construcción de significado. Esto es posible dado que cada recurso o estrategia implicada en la construcción discursiva contribuye a representar de una manera particular el fenómeno al que hace referencia.

Es usual que en la interacción cotidiana, en la actividad comunicativa mediática $y$, en general, en todas las formas de expresión humana, se reconozcan los recursos y las estrategias que dan cuenta del propósito de quien se expresa: convencer, persuadir, seducir o engañar, entre otros. El uso de estos recursos y estrategias retóricas puede contribuir a imponer un punto de vista o una manera de explicar la realidad, todo lo cual tiene efectos sobre la práctica de los actores sociales.

Para ilustrar se verifican las maneras en que los medios de comunicación, en particular la prensa, proponen a sus interlocutores, uno de los problemas más estructurales en América Latina. La pobreza es representada haciendo uso de recursos como las metáforas. Este uso de la lengua sirve al propósito de naturalizar el problema social como en el titular "Cosecha de Pobreza e Indigencia". 9 Entre las múltiples inferencias que se derivan de una expresión como la de este titular de prensa, se establece que la pobreza es un vegetal, se cultiva, produce frutos, etc. Lo que se deriva de esta manera de representar la realidad es, por una parte, que la pobreza es un elemento constituyente de la naturaleza y, por otra parte, que sus frutos son un haber social.

En este caso, no solo se propone una representación limitada del fenómeno social, sino que al naturalizarlo y convertirlo en parte

9. El Tiempo.com, 28 de agosto de 2003. Editorial-opinión. Abdón Espinosa Valderrama. 
de las condiciones biológicas disponibles, se oculta la responsabilidad histórica, política y social que les compete a los actores sociales. Esta responsabilidad involucra elites políticas, económicas y culturales, que despliegan estrategias conducentes a ocultar las particularidades de un fenómeno colectivo que se ubica en el marco de estructuras sociales definidas en las correlaciones de fuerza de los actores implicados. Además, el sentido de abundancia desdibuja el carácter inequitativo y excluyente de los fenómenos de la pobreza y la indigencia.

Los discursos de la prensa pueden reforzar el carácter amenazante de un fenómeno social, cuando a través del uso de recursos retóricos minimizan, magnifican o espectacularizan, recurriendo al uso de expresiones hiperbólicas del tipo "En 2010, 39 millones de pobres más". ${ }^{10}$ El parámetro es una cifra que argumenta el carácter verdadero, o por lo menos verosímil del dato. El sistema inferencial que se deriva de este titular permite identificar la transposición del problema social a una condición individual, a partir de lo cual se focaliza en la cantidad de personas que son representadas como pobres y no en la compleja problemática social de la pobreza. Además, el sentido de inseguridad que suscita esta expresión procede de la manera como en el mundo occidental se ha asociado el fenómeno con problemáticas tales como la delincuencia, la violencia, la suciedad, la hostilidad y, en general, el conjunto de condiciones valoradas negativamente y que constituyen puntos de tensión social.

Cada uno de los recursos retóricos usados en el proceso de producir significado, no sólo desempeñan la función semántica de representar de una determinada manera la realidad, sino que condicionan el proceso de interpretación. El conjunto de saberes implicados contribuyen a orientar la acción social. Además, los recursos retóricos desempeñan función pragmática cuando crean estrategias de adecuación discursiva, propiciando que los discursos no sólo sean más atractivos y se instalen de manera más fácil en la memoria, sino creando en el proceso de persuasión, relaciones simples

10. El Tiempo.com, 01 de diciembre de 2009. Nación. 
no controvertibles, que se acercan a la experiencia social estabilizada. En consecuencia, el potencial nemotécnico de la utilización del los recursos retóricos se concreta en la estabilización de los saberes disponibles en relación con una problemática social, así como en la vigencia y relevancia de estos asuntos en la agenda pública.

En el titular "Escoja un pobre y sáquelo de pobre"11, la representación incluye, en primer lugar, la idea de que quienes sufren pobreza deben ser expuestos a exhibición para ser seleccionados por otros. De esta manera, se propone una lógica de mercado y se objetualiza al ser humano que está en condición de pobreza. Esta racionalidad instrumental de tipo costo-beneficio se expresa en la posibilidad de satisfacer un deseo moral, que desconoce la alteridad de quienes se representan como medios para la satisfacción de los intereses de quienes tienen la posibilidad de elegir. En segundo lugar, la responsabilidad social es de orden individual y se sujeta a un ideario paternalista, que se ubica en el ámbito de lo privado. Esta lógica, además, incluye el sentido de la caridad, evocando principios morales como el altruismo, la benevolencia, la generosidad, la clemencia y la comprensión.

Lo que se deriva de esta forma de representar al pobre y a la pobreza, incluye la transferencia de la responsabilidad del Estado para garantizar las condiciones de dignidad y bienestar a la que tiene derecho todo ciudadano. A través de la estrategia retórica, se abroga la responsabilidad estatal a quienes desean o se sienten en obligación de asumir la tarea paliativa de atender alguna necesidad vital o básica de un ser humano. El efecto ideológico que de esto se deriva consiste en la reificación de la acción individual, y en la construcción de la expectativa de que es posible desde decisiones individuales disponer del destino de los pobres. Se elide el hecho de que la pobreza es un fenómeno relacional y, por consiguiente, que la responsabilidad de resolverla atañe al conjunto de los actores sociales. Además, se desconoce el hecho de que la superación de

11. El Tiempo.com, 20 de enero de 2002. Editorial - opinión. Alfonso Llano Escobar, S.J. 
la pobreza, en tanto fenómeno social, implica la realización de reformas estructurales que alteren las formas en que los actores sociales acceden a los recursos simbólicos y materiales.

En el titular: "No saben planificar. Los hijos de la pobreza", se hace evidente que lo que se expresa desde la perspectiva de quien representa la pobreza, dota al discurso de una gran carga de subjetividad y de posturas personales que introducen elementos marcadamente valorativos. Lo que se infiere incluye no sólo la pobreza material, sino la cognitiva. Además, la valoración introducida alude a consideraciones éticas en torno a lo que se supone es responsabilidad de los sujetos referenciados. El titular propone la idea de que los pobres tienen ciertas características y que ellos son responsables de sus condiciones de vida. Estas condiciones se vinculan discursivamente, por una parte, al proceso reproductivo - con todas las cargas negativas que esto implica para la vida moderna- y, por otra, a su condición de ignorantes.

La falacia procede de la valoración propuesta y de la generalización, según la cual lo que se atribuye es inherente a ese grupo poblacional. El titular contribuye, por lo tanto, a reforzar el sentido de perpetuación e irresolubilidad del fenómeno, y desconoce que el problema del acceso a la educación se articula integralmente a las condiciones de vida, que una sociedad y que el Estado debe garantizar. La ignorancia de un grupo, por lo tanto, no procede de la responsabilidad de los individuos, sino de la ausencia de un conjunto de garantías para el acceso a los derechos. La representación que se deriva del titular constituye un recurso cognitivo que, en virtud de su potencial de circulación social derivado de la institucionalidad de la prensa y de la capacidad tecnológica para distribuir conocimiento, orienta prácticas sociales discriminatorias y excluyentes, que refuerzan la marginalización de sectores sociales cuya condición se explica a partir de referentes económicos, históricos, políticos y culturales. 


\section{Consideraciones finales}

Como se ha venido indicando, las experiencias de grupo sociales, de instituciones y de las personas se representan en distintos tipos de modelos cognitivos de contexto, a través de los cuales se organizan los saberes, las creencias y, en general, las maneras como los idearios compartidos se estructuran como ideologías. Los saberes que constituyen las ideologías son compartidos por los grupos y los miembros de cada grupo. Este fenómeno socio cognitivo explica por qué los grupos humanos se organizan en torno a valoraciones que incluyen evaluaciones positivas para sí mismos y el grupo del cual se forma parte, así como evaluaciones negativas que se expresan con frecuencia en prejuicios sobre los "otros" y sobre el grupo al que "ellos" pertenecen (van Dijk. 1999). Este fenómeno puede rastrearse en la actividad comunicativa.

En esta reflexión no se teoriza de manera amplia la noción de género en tanto categoría que contribuye a dar cuenta del contexto en su dimensión cognitiva. Se verifica que el género es una propiedad de los discursos que, entre otras características, permite reconocer su carácter hibrido, en la medida en que un género puede articular múltiples combinaciones de los rasgos distintivos de otros géneros. Además, el conjunto de propiedades que definen la tipicidad de un género procede de sus características contextuales: el escenario en términos espacio temporales; los participantes con sus roles, identidades y relaciones; el ámbito de la acción social, así como lo que se representa en términos de los saberes, las creencias y los propósitos comunicativos. De esta forma, se pueden reconocer las ideologías propuestas. Los géneros comparten unas categorías que se instalan en la estructura discursiva y en el contexto. Los datos empíricos analizados, que se seleccionaron para el estudio y la discusión permiten afirmar que el discurso mediático representa, con relativa frecuencia, grupos sociales marcados por prejuicios y estereotipos, que contribuyen a discriminar y en ocasiones a profundizar el sentido 
de desigualdad social y de cierto modo, "naturalizar" la cuestión de la pobreza.

denizelena@gmail.com neylapardo@yahoo.com//pardo.neyla@gmail.com

\section{Referencias bibliográficas}

ALBALADEJO, T. Retórica. Madrid: Síntesis, 1989.

BAJTIN, M. Estética de la creación verbal. Madrid: Siglo XXI editores, 1985. BARBARA, L. y MACEDO, C.M.M. Lingüística Sistêmico-Funcional para a Análise de Discurso: um panorama introdutório. In: Cadernos de Linguagem e Sociedade, vol. 10(1), 2009, p. 87-105.

CHOULIARAKI, L., \& FAIRCLOUGH, N. Discourse in Late Modernity. Rethinking Critical Discourse Analysis. Edimburgo: Edinburgh University Press, 1999.

DIJK, T. van. Las estructuras y funciones del discurso. México: Siglo XX, 1981.

DIJK, T. van. Ideología. Barcelona: Gedisa, 1999.

DIJK, T. van. El discurso como interacción en la sociedad. In: T. van Dijk (comp.), El discurso como interacción social. Barcelona: Gedisa, 2001.

DIJK, T. van. La multidisciplinariedad del análisis crítico del discurso: un alegato a favor de la diversidad. In: R. Wodak y M. Meyer (comps.) Métodos de análisis crítico del discurso, trad. de T. Fernández y Beatriz Eguibar. Barcelona: Gedisa Editorial, 2003.

DIJK, T. van. Racismo y discurso en América Latina. Barcelona: Gedisa, 2007.

DIJK, T. van. Discourse and context. A sociocognitive approach. Cambridge: Cambridge University Press, 2008.

DIJK, T. van. Discurso y poder. Barcelona: Gedisa, 2007.

DRESSLER, W.U. \& DE BEAUGRANDE, R. Introduction to Text Linguistics. London: Longman, 1981. 
ECO, U. La estructura ausente. Introducción a la semiótica. Barcelona: Lumen, 1983.

GHIO, E. y FERNÁNDEZ, M. D. Lingüística Sistemico Funcional. Aplicaciones a la Lengua Española, $1^{\text {a }}$ ed. Santa Fe: Universidad Nacional del Litoral, 2008.

GRUPO $\mu$. Tratado del signo visual. Madrid: Cátedra, 1993. HALLIDAY, M.A.K \& HASAN, R. Functions of language. In: Language, context, and text: Aspects of language in a social-semiotic perspective. Oxford: Oxford University Press, 1989.

KRESS, G. \& Theo Van LEEUWEN. Reading Images: The Grammar of Visual Design. London: Routledge, 1996.

LEECH, G. A Linguistic Guide to English Poetry. London: Longman, 1969. MARTIN, J. Duelo: Cómo nos alineamos, trad. Elza Guio. In: Discurso \& Sociedad, vol. 4(1), 2010, p. 120-150.

MARCUSCHI. L.A. Produção textual, análises de géneros e compreensão. São Paulo: Parábola Editorial, 2008.

MARCUSCHI, L. A. O papel da atividade discursiva no exercício do controle social. In: Cadernos de Linguagem e Sociedade, vol. 7. Brasília: Thesaurus Editora, 2005.

MEURER, J.L. Integrando estudos de gêneros textuais ao contexto de cultura. In: Karwoski, A. et all. (org.). Gêneros textuais: reflexões e ensino, $2^{a}$ ed. RJ:Lucerna, 2006.

PARDO GIL, L. (2008). Investigar el discurso de la pobreza hoy en América Latina. In: El discurso sobre la pobreza en América Latina. Santiago de Chile: Frasis Editores, 2008.

PARDO, N. ¿Qué nos dicen? ¿Qué vemos? ¿Qué es... pobreza? Análisis Crítico de los medios. Bogotá: Antiquus Ed., 2008.

POCHMANN. M, AMORIM, R. (orgs.). Atlas da exclusão social no Brasil, $3^{\mathrm{a}}$ ed. São Paulo: Cortez Editora, 2004.

TODOROV, T. Literatura y significación. Barcelona: Planeta, 1974.

SILVA, D.E.G. e RAMALHO, V. Análise de Discurso Crítica: representações sociais na mídia. In: Lara, G.M. Machado, Ida L. Emediato, W. Análises do discurso hoje. vol. 2. Rio de Janeiro: Nova Fronteira (Lucerna), 2008. 
SILVA, D.E.G. Representações discursivas da pobreza e discriminação na mídia. In: D.E.G. da Silva, Leal, M.C.D. e Pacheco, M.C.N. (orgs.), Discurso em questão: representação, gênero, identidade, discriminação. Goiânia: Cânone Editorial, 2009.

SILVA, D.E.G. Identidades enfraquecidas versus cidadania cultural. In: Sébastien, J. (org.), Colóquio Cidadania Cultural: diversidade cultural, linguagens, identidades, vol 2. Recife: Editora Universitária (UFPE), 2007.

WODAK \& MEYER (orgs.) Métodos de Análisis Crítico del Discurso, trad. de Tomaz Fernández y Beatriz Eguibar. Barcelona: Gedisa, 2003.

\section{Referencia del corpus}

http://bp2.blogger.com/GGlC2YPPyV4/RilX79b0zkI/.jpg - aceso el 24 de mayo de 2010. 